University of Montana

ScholarWorks at University of Montana

$10-2006$

\title{
Consumers Limit the Abundance and Dynamics of a Perennial Shrub with a Seed Bank
}

Matthew J. Kauffman

John L. Maron

University of Montana - Missoula, john.maron@mso.umt.edu

Follow this and additional works at: https://scholarworks.umt.edu/biosci_pubs

Part of the Biology Commons

Let us know how access to this document benefits you.

\section{Recommended Citation}

Kauffman, Matthew J. and Maron, John L., "Consumers Limit the Abundance and Dynamics of a Perennial Shrub with a Seed Bank" (2006). Biological Sciences Faculty Publications. 203.

https://scholarworks.umt.edu/biosci_pubs/203

This Article is brought to you for free and open access by the Biological Sciences at ScholarWorks at University of Montana. It has been accepted for inclusion in Biological Sciences Faculty Publications by an authorized administrator of ScholarWorks at University of Montana. For more information, please contact

scholarworks@mso.umt.edu. 


\section{Consumers Limit the Abundance and Dynamics of a Perennial Shrub with a Seed Bank}

\author{
Matthew J. Kauffman ${ }^{\star}$ and John L. Maron ${ }^{\dagger}$ \\ Division of Biological Sciences, University of Montana, Missoula, \\ Montana 59812 \\ Submitted October 16, 2005; Accepted June 14, 2006; \\ Electronically published September 6, 2006 \\ Online enhancement: appendix.
}

leaves, or other plant parts can negatively influence key fitness components such as plant growth, fecundity, and survival (reviews in Louda 1989; Gange 1990; Huntly 1991; Marquis 1992; Stowe et al. 2000). Although our understanding and cataloging of how consumers affect individual plant fitnesses continues to expand, we still have limited insight into how these individual effects translate to long-term patterns of plant population growth, dynamics, and distribution (Crawley 1989; Hunter 1992; Louda and Potvin 1995; Herrera et al. 2002; Strauss and Zangerl 2002). Consumers, especially those that are not large mammalian browsers, do not figure prominently in theories of plant dynamics. Traditionally, edaphic factors and plant competition have been considered primary determinants of local patterns of plant abundance.

Appreciation of the role that consumers play in shaping plant dynamics has been hindered by the dearth of experiments that fully detail how consumers influence plant demography. Most experimental studies on plant-consumer interactions are short-term and examine consumer effects on only one or a few stages in a plant's life cycle (Ehrlén 2002). For example, there have been numerous studies of how pre- or postdispersal seed predators influence plant fecundity and seed fate (Hendrix 1984; Mittelbach and Gross 1984; Auld and Myerscough 1986; Zammit and Hood 1986; Andersen 1988, 1989; Louda 1989; Crawley 1992; Hulme 1994, 1998; Ehrlén 1997; Edwards and Crawley 1999; Cummings and Alexander 2002). Yet these studies are generally uninformative regarding population-level impacts of consumers because they fail to examine the demographic consequences of herbivory and granivory across the entire plant life cycle. The same is true in cases where herbivores attack and kill seedlings (Cates 1975; Dirzo and Harper 1982; Parker and Salzman 1985; Hulme 1994; Hanley et al. 1995; Goheen et al. 2004). As a result, it is unclear how processes that occur at one portion of a plant's life cycle either limit or exacerbate negative consumer effects that occur at other life stages.

Theory provides several reasons why negative impacts of consumers may not translate to population-level effects. First, density-dependent processes are important in many

\footnotetext{
Am. Nat. 2006. Vol. 168, pp. 454-470. (C) 2006 by The University of Chicago. 0003-0147/2006/16804-41364\$15.00. All rights reserved.

* Corresponding author. Present address: Wyoming Cooperative Fish and Wildlife Research Unit, U.S. Geological Survey, University of Wyoming, Laramie, Wyoming 82071; e-mail: matt.kauffman@mso.umt.edu.

† E-mail: john.maron@mso.umt.edu.
}

Most plants are attacked by consumers at some stage of their life cycle. Consumption of seeds, seedlings, roots, 
plant populations. If density dependence is compensatory, then reductions in plant numbers (either from negative effects of seed predators on seedling recruitment or from outright consumer-driven mortality of seedlings or established plants) may not influence long-term patterns of plant abundance. Harper (1977) encapsulated this idea by suggesting that because of density-dependent mortality, there is a "tolerable" amount of seed predation that will not have population-level effects. The influence of seed predators in particular may be strongly mediated in safesite-limited systems. In this form of compensatory density dependence, the number of safe sites that are available for germination and successful seedling establishment sets the limit on recruitment; effects of seed loss will be negligible unless seed predators reduce the seed input below the amount necessary to saturate safe sites. Finally, many plants have persistent seed banks. Dormant seeds can either saturate safe sites themselves or provide a source of potential recruits that can compensate for occasional low years in seed production caused by heavy herbivory and granivory (Crawley 1989, 1992, 1997).

Thus, while the injurious impacts of consumers on plants are manifold, the complexity of population processes has limited our general understanding of how and when they influence long-term population dynamics. Population models can be effective tools for gaining insight into the long-term population level consequences of consumers on plants, but these have only recently been employed in experimental plant-herbivore studies (Ehrlén 1995, 2003; Fröborg and Eriksson 2003; Rose et al. 2005). Perhaps one reason why this has been so is that incorporating density dependence as well as information on seed dormancy into these models is challenging; often, data on these critical processes are lacking. In fact, we know of no work where these processes have been incorporated into population models to ask how consumers influence the abundance of plant populations that may not be at equilibrium. In conservation scenarios, assessing the viability of rare plants is also problematic without some data on seed dormancy (Doak et al. 2002).

In this study, we evaluate the influence of several consumers on the population dynamics of bush lupine $(\mathrm{Lu}$ pinus arboreus), a perennial shrub that grows in both dune and grassland habitats. On the basis of a 5.5-year experiment where lupine populations were either protected from or exposed to rodents, we know that these consumers can have strong but habitat-specific impacts on plants. In dunes, postdispersal seed predation by mice (Peromyscus maniculatus and Reithrodontomys megalotus) reduces lupine seed abundance and limits seedling recruitment (Maron and Simms 2001; Maron and Kauffman 2006). In grasslands, postdispersal seed predation by mice is much more limited, but vole (Microtus californicus) predation on seedlings can be intense (as it occasionally can be in dunes), although the magnitude of seedling predation varies enormously among years as vole populations wax and wane (Maron and Simms 1997; Maron and Kauffman 2006). Figure 1 summarizes these varied demographic effects. While the effects of consumers on seed and seedling survival can be substantial, several factors potentially limit the strength with which these reductions in performance actually influence lupine populations. First, as in many plants, density dependence operates on seedling survival. Seed dispersal is local (relatively heavy lupine seeds dehisce explosively from seed pods), seedlings recruit nearby existing adult shrubs, and adult shading limits seedling survival (Maron and Kauffman 2006). Second, both mice and voles attack early life stages of lupine. Because population growth often has low sensitivity to variation in demographic rates of early plant life stages (Silvertown et al. 1993; Fröborg and Eriksson 2003; Franco and Silvertown 2004), a central question concerns whether large effects on seeds or seedlings scale up to influence population dynamics. Here, we use population models to assess how reductions in plant performance at these early life stages influence plant population dynamics. We also use our parameterized demographic models to explore how the strengths of density dependence and seed dormancy mediate population-level effects of consumers.

\section{Study System}

This work was conducted on the 147-ha University of California Bodega Marine Reserve (BMR) along the coast of central California, where bush lupine is native. On the BMR, bush lupine grows in adjacent grassland and dune habitats, where individual shrubs can live approximately 8-12 years. Lupine seedlings recruit into populations during the rainy season, from December to March. The majority of plants begin to set seed in their second (grasslands) or third (dunes) summer; dispersed seeds are often consumed by mice (Maron and Simms 1997, 2001), but they do not appear to be regularly eaten by granivorous birds (E. L. Simms, unpublished data), and there are no seed-harvesting ants at our site. Lupines have a hard seed coat and a physically enforced seed dormancy that is broken by scarification or heating and cooling of the soil in late summer (Hyde 1954; Rolston 1978). Bush lupine seeds can remain dormant but viable in the soil for many years (J. L. Maron and E. L. Simms, unpublished data).

\section{Methods \\ General Approach}

We built and parameterized population models using experimental demographic data collected in grassland and 

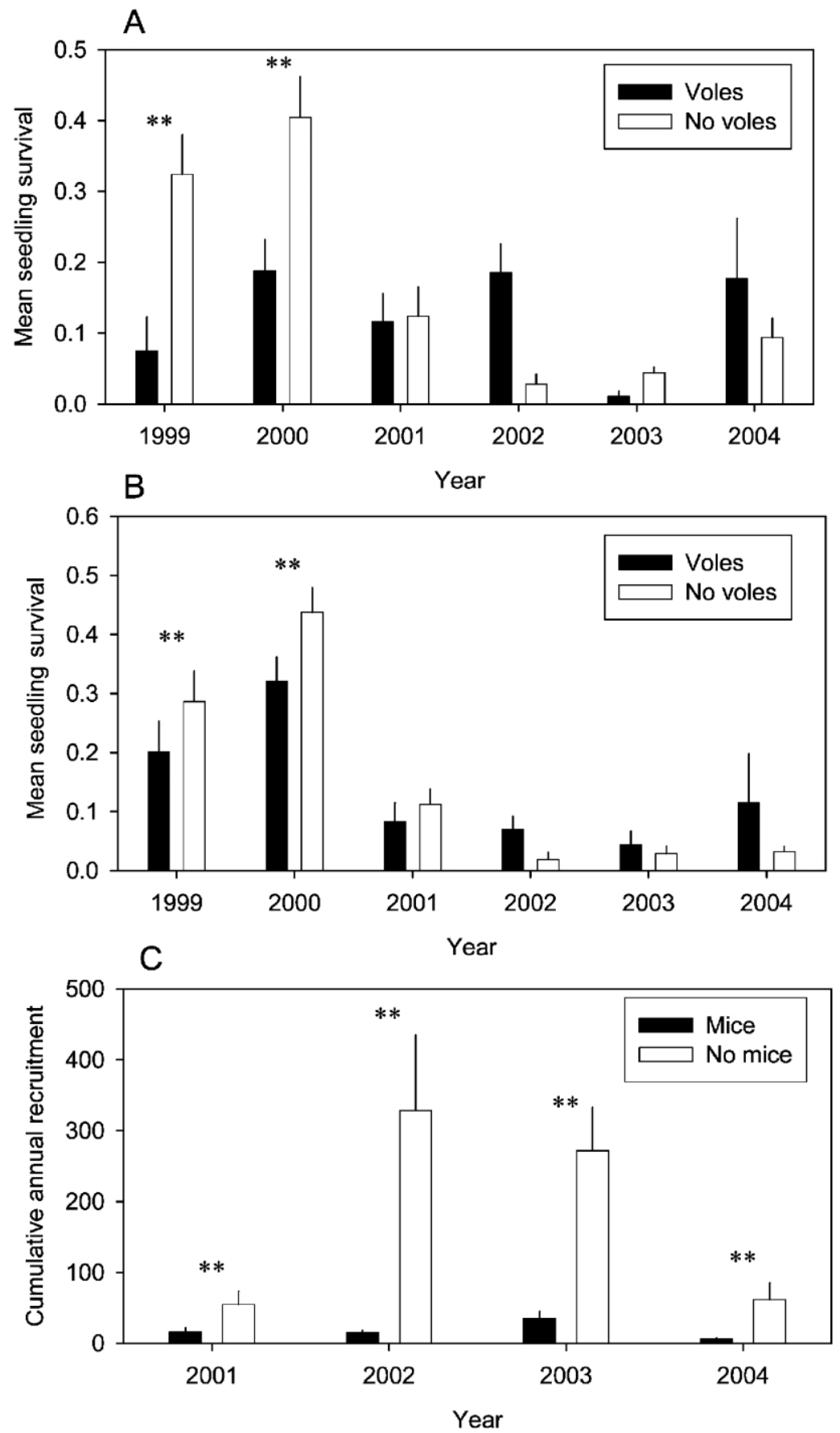

Figure 1: Effects of mice and voles on the demography of lupine seeds and seedlings in dune and grassland habitats. A, In the grasslands, voledriven reductions in seedling survival were periodic, with significant reductions in survival occurring in 1999 and 2000 . B, In the dunes, voles reduced seedling survival in the first 2 years of the experiment but had no effects thereafter. $C$, Seed predation by mice in the dunes substantially reduced seedling recruitment in all years. Tests for significant effects by year (indicated by double asterisks) were conducted by Maron and Kauffman (2006). 
dune habitats. In past experiments, we quantified how voles and mice influenced particular demographic transitions in these distinct habitats (Maron and Kauffman 2006). Here, we varied these parameters in population models, keeping other transitions not influenced by these consumers constant, allowing us to ask how the presence or absence of rodents influences long-term population size and short-term population growth of lupine in grasslands and dune habitats. In most instances, we estimated all of the necessary demographic rates in both habitats using standard methods. A few demographic parameters, however, such as seed germination and seed predation, were impossible to measure directly, so we used model-fitting techniques to estimate these rates. Although we used mean demographic rates (from multiple observations across years) in our matrix, we bootstrapped from the original data sets to assess how the uncertainty in our estimates of demographic parameters influenced model outcomes.

\section{Aboveground Demographic Rates}

Demographic information was gathered from a replicated experiment established in both habitats in 1998. This experiment is described fully elsewhere (Maron and Kauffman 2006), so we only summarize it briefly here. The experiment consisted of two experimental blocks at each of three grassland and dune sites. Within each experimental block, we established four $9 \times 9$-m plots ( 24 plots per habitat, 48 plots total) randomly assigned to one of four factorial combinations of with/without rodent exclusion and with/without belowground insect herbivore exclusion. Since effects of belowground insect herbivores were minimal during the course of this experiment (Maron and Kauffman 2006), we estimated lupine vital rates with respect to rodent presence or absence, while ignoring the minimal effects of insects. Rodents were excluded from plots by $90-\mathrm{cm}$-tall fences made of PVC-coated welded wire $(0.635-\mathrm{cm}$ mesh), dug $30 \mathrm{~cm}$ into the ground, and topped with $22.5 \mathrm{~cm}$ of aluminum flashing. Control plots open to rodents were surrounded by an identical meshsize welded-wire fence (but without PVC coating or flashing) that had 5-cm-diameter holes cut every $1.5 \mathrm{~m}$ along the bottom of each fence line to allow entry by rodents. Rodent exclusion plots did not independently manipulate voles and granivorous mice but instead protected experimental lupine populations from all rodents. However, we could easily separate vole and mice effects on lupine demography because mice attack only lupine seeds, whereas voles kill only seedlings.

In January 1999, we transplanted 49 lupine seedlings in an equally spaced grid pattern across each plot. Experimental plots in the grasslands were initially free of existing lupine because of a large lupine die-off in the grasslands in the summer of 1997 (Maron et al. 2001). Lupines, however, did not die off in dunes in 1997, so we cleared the few existing lupines from dune plots in 1998 to ensure that experimental populations in both habitats started with identical numbers of plants. Because of high vole herbivory and high rates of seedling mortality of individuals planted in 1999, in January 2000 we transplanted an additional 20 marked seedlings in randomly selected open spaces between the surviving plants in each plot. In 1999 and 2000, we removed any seedlings that naturally recruited into plots so that we could start experimental populations at similar densities. In subsequent years (2001-2004), no new seedlings were planted, and natural recruitment was allowed to occur. From January/February 1999 through April 2004, we censused all lupines in experimental plots during the growing season (January-August), marking and following the fate of new recruits and censusing previously marked plants. We conducted a final census of plants in early September 2004. We estimated seed production on all marked plants by counting all seed pods on every plant in each plot each summer. To determine the number of seeds produced per pod, we harvested 15 randomly chosen seed pods on each of 10 shrubs per plot and counted the number of intact seeds per pod. At the end of a plant's second summer (July-August), its canopy area was measured in two perpendicular directions, and each plant's size was estimated as its circular area calculated from the two canopy diameter measurements.

Nine stage classes were identified to capture the lupine life-history schedule. Through graphical inspection of the data, size boundaries for stage transitions were set small enough to take account of size-specific patterns of seed production and survival but broad enough to provide reasonable estimates of growth, survival, and fecundity (see table A1 in the online edition of the American Naturalist). Because we did not record the size of plants in their first summer, when plants were still small seedlings, we defined the first stage to include all 1-year-old plants regardless of size. Thus, in their first year, plants could only transition from seeds to the 1-year-old stage. In subsequent years, 1-year-old plants could survive and grow to a larger stage class based on empirical estimates of stage-specific growth and survival. Because preliminary analyses indicated no treatment effects on growth, survival, and fecundity of lupines 1 year old or older (J. L. Maron and M. J. Kauffman, unpublished data), we used plants from all plots within each habitat to estimate these rates. Because consumers reduce the survival of seedlings in this system (Maron and Kauffman 2006) and because seedling survival is potentially controlled by adult plant density, we estimated seedling survival as a function of treatment and density (see "Density-Dependent Seedling Survival"). 


\section{Rates of Seed Germination and Dormancy}

For plants that produce dormant seeds, the seed pool from which seeds germinate each winter (beginning in December) consists of "new" seeds that were produced the previous summer and "banked" seeds that have been previously dormant in the seed bank. Because banked seeds are themselves the result of historical seed production, estimating germination rates in a natural population requires accounting for seed production from current and previous reproduction. To estimate habitat-specific germination rates within the context of seed bank dynamics, we used a model-fitting approach whereby the number of emerging seedlings was a function of the number of banked and new seeds in the seed pool. This approach had some advantages over experimental burying of bagged seeds in that we did not have to alter the timing of seed rain, seed density, or the spatial distribution of seeds in the soil. Artificially high seed densities in seed addition experiments can result in spurious estimates of germination rates (Van Mourik et al. 2005).

Our modeling approach assumed that the number of seedlings emerging in each experimental plot in each spring is the proportion of seedlings emerging from the available seed pool (denoted as pool below). This is described as

$$
s d \operatorname{lngs_{i,t+1}}=\text { pool }_{i, t} g_{\mathrm{hab}}
$$

where $s d \operatorname{lngs} s_{i, t+1}$ is the number of seedlings in plot $i$ at time $t+1$, pool $_{i, t}$ is the number of seeds in the seed pool of plot $i$ at time $t$, and $g_{\text {hab }}$ is the habitat-specific emergence rate of seedlings from the seed pool. Here, we assume that new and banked seeds emerge in the winter at the same rate, $g_{\text {hab }}$, within a habitat, and the seed bank (eq. [2]) is modeled to include seeds produced in the previous year. We include an emergence rate $\left(g_{\text {hab }}=\right.$ proportion of seeds that become seedlings) rather than a germination rate in these models because we could not measure germination rate directly in the field. Because some seeds may germinate and fail to emerge, this method probably overestimates the proportion of seeds that remain in the seed bank. Hereafter, we use "seed germination" and "seedling emergence" interchangeably, although, strictly speaking, seedling emergence rates incorporate both seed germination and seed death.

A second difference equation was used to keep track of the number of seeds in the seed pool of each plot:

$$
\begin{aligned}
\operatorname{pool}_{i, t}= & \operatorname{bank}_{i, t-1}\left(1-g_{\text {hab }}\right) S_{\text {seeds }}\left(1-p_{\text {bank, hab }}\right) \\
& +\operatorname{seeds}_{i, t}\left(1-p_{\text {new, hab }}\right)
\end{aligned}
$$

where bank $_{i, t-1}$ is the number of seeds in the seed bank at time $t-1$, seeds $s_{i, t}$ is the number of seeds produced in plot $i$ in the current year $t, S_{\text {seeds }}$ is the survival rate of seeds that remain in the seed bank (fixed at 0.72; Maron and Simms 1997), and $p_{\text {new, hab }}$ and $p_{\text {bank, hab }}$ are the habitatspecific predation rates on new and banked seeds, respectively. In our model fitting, we fitted $p_{\text {new, hab }}$ and set $p_{\text {bank, hab }}$ to be a constant fraction of $p_{\text {new, hab }}$ based on the proportion of seeds consumed in surface and buried seed predation trials conducted by Maron and Simms (1997). Based on this earlier study, seed predation on banked seeds was always modeled as $22 \%$ of $p_{\text {new }}$ in the dunes and $38 \%$ of $p_{\text {new }}$ in the grasslands. However, since $p_{\text {new }}$ in grasslands is 0 (see "Results"), the model effectively has no predation on banked seeds in the grassland.

Previous work at our study site revealed that the lupine seed bank size differs dramatically between dune and grassland habitats (Maron and Simms 1997; Maron and Kauffman 2006). In the dunes, only a small seed bank exists (approximately 7-42 seeds $/ \mathrm{m}^{2}$ ), whereas the grassland supports an abundant seed bank (approximately 300 seeds/ $\mathrm{m}^{2}$; Maron and Simms 1997). To account for these differences in seed bank density between habitats (scaled by our $81-\mathrm{m}^{2}$ plot size), we initialized our model runs using an average seed bank of 24,000 seeds in the grassland and 2,000 seeds in the dune habitat.

Within a habitat, rates of both seed predation and germination influence the proportion of seeds that become seedlings. However, it is impossible to fit these two rates simultaneously while fitting equations (1) and (2) to seedling data collected in experimental plots. To solve this complication, we first used data from plots $(n=24)$ that were closed to rodents (the only postdispersal seed predators in this system) to test for and estimate a habitatspecific rate of seed germination $\left(g_{\text {hab }}\right)$. Once we had estimated the effects of habitat on germination rate using the 24 rodent exclusion plots from both habitats, we held germination rates at their habitat-specific values while fitting the rate of seed predation in equation (2) to seed and seedling data from plots open to rodents $(n=24)$.

We used maximum likelihood and Akaike Information Criterion (AIC) techniques (Burnham and Anderson 2002) to assess the support from our field data for alternative forms of equations (1) and (2). We fit each alternative model to the field data on the number of seedlings emerging in each plot for the years 2001-2004, when natural recruitment occurred. Because initial inspection of the data indicated strong between-year differences in germination, we always included a year effect on germination rate. Thus, we tested two germination models, a model with year effects only and a model with year and habitat effects. We did not test for interactions between year and habitat. Model fitting allowed us to chose the model and parameter values that reduced the variation between the 
predicted and observed number of emerging seedlings. The total negative log likelihood (NLL) of model $i$ is the sum of each of $T=4$ yearly negative log likelihoods in each of the $j=24$ rodent exclusion plots (when estimating emergence) and the $j=24$ control plots (when estimating seed predation), given the number of emerging seedlings, $s d l n g s_{i, t+1}$, observed in each plot in each year:

$$
\mathrm{NLL}\left(\text { model }_{i} \mid \text { data }\right)=\sum_{j=1}^{24} \sum_{t=1}^{T} \mathrm{NLL}\left(\operatorname{model}_{i} \mid \operatorname{sdlngs}_{i, t}\right) .
$$

For data for a given plot $i$ in year $t$, the negative $\log$ likelihood of model $i$ is

$$
\operatorname{NLL}\left(\operatorname{model}_{i} \mid s d \operatorname{lng} s_{i, t}\right)=-\ln \left[\operatorname{Pr}\left(\operatorname{sdlngs}_{i, t} \mid \text { model }_{i}\right)\right],
$$

where $\operatorname{Pr}\left(\operatorname{sdlngs}_{i, t} \mid\right.$ model $\left._{i}\right)$ is the probability of generating the number of seedlings in year $t$ in plot $j$ given the parameter values and structure of model $i$. We assumed normally distributed within-year observation errors and no process error, resulting in

$$
\begin{aligned}
-\ln & {\left[\operatorname{Pr}\left(\operatorname{sdlngs}_{i, t} \mid \operatorname{model}_{i}\right)\right]=\log (\sigma) } \\
+ & \frac{1}{2} \log (2 \pi) \\
+ & \frac{\left[\operatorname{sdlngs}_{i, t}-\operatorname{sdlng} s_{i, t \text { (pred })}\right]_{2}}{2 \sigma^{2}}
\end{aligned}
$$

(Hilborn and Mangel 1997), where $s d l n g s_{i, t(\text { pred })}$ is the number of emerging seedlings predicted by model $i$ to be in plot $j$ at time $t$ and $\sigma^{2}$ is the fitted variance. Best-fit parameters of alternative models were obtained using the nonlinear solver NPSOL in the TOMLAB optimization environment (Holmstrom 1999). All optimizations were implemented in MATLAB (version 6.0.0.88, release 12, Mathworks). We calculated the small-sample-corrected AIC value $\left(\mathrm{AIC}_{\mathrm{c}}\right)$ for each alternative model $i$ as $\mathrm{AIC}_{c_{i}}=2 \mathrm{NLL}_{i}+2 p_{i} n /\left(n-p_{i}-1\right)$, where $p_{i}$ is the number of parameters in model $i$ and $n$ is the sample size.

To compare the relative support between models, we calculated the AIC weight of each model (Burnham and Anderson 2002). Because AIC weights of all models in a candidate set sum to 1 , they estimate the proportional support of the data for each alternative model. We assessed the relative support of distinct model components (which may be included in several models) by summing the AIC weights of all models that include the component of interest (Burnham and Anderson 2002). We estimated 95\% confidence limits for each fitted parameter in the best-fit model using likelihood profiles (Hilborn and Mangel
1997) or by bootstrapping from the original data where necessary.

\section{Density-Dependent Seedling Survival}

Our empirical work strongly suggested that in years of low adult abundance, seedling survival could be quite high, but that, at least in some years, lupine populations are limited by high seedling mortality (Maron and Kauffman 2006). These biological considerations suggested that density-dependent seedling survival was important. We incorporated this form of density dependence into our population models by fitting both the Ricker model,

$$
S_{\text {sdlng }}=\left(\beta_{1}+\beta_{2} \text { rodent }\right) \exp \left(-\beta_{3} \operatorname{cov}\right),
$$

and the Beverton-Holt model,

$$
S_{\text {sdlng }}=\frac{\beta_{1}+\beta_{2} \text { rodent }}{1+\beta_{3} \operatorname{cov} t},
$$

to the seedling survival data. In these equations, rodent is a categorical variable classifying plots as open or closed to rodents, $c o v_{t}$ is the cover of adult lupines in each plot in year $t$, and $\beta_{1}-\beta_{3}$ are fitted parameters. The main difference between these two functional forms of density-dependent seedling survival is how they perform at high densities. The Beverton-Holt model is compensatory, allowing a constant number of survivors at high density; the Ricker model allows the rate of seedling survival to continue to decline at higher densities (Morris and Doak 2002). Cover at the plot level was calculated by summing the circular canopy areas of all plants in the plot. The small contribution to total cover made by seedlings themselves was not included in this analysis. Model fitting was performed using PROC NLIN in SAS (Seber and Wild 1989). We judged the fit of these two functional forms using Akaike weights derived from the small-sample version of the AIC (AIC; Burnham and Anderson 2002). Because we have shown previously that seedling survival is habitat specific (Maron and Kauffman 2006), we used likelihood ratio tests, conducted separately in each habitat, to assess the significance of the effects of voles and lupine cover on seedling survival.

\section{Model Structure and Methods for Estimating Mean and Variance in Population Metrics}

We used a size-based matrix projection model (Lefkovitch 1965; Caswell 2001) to evaluate the effects of seed predation by mice and seedling mortality by voles on lupine population performance in dune and grassland habitats. Our population model was deterministic and had the form 
$\mathbf{n}(t+1)=\mathbf{A}(t) \mathbf{n}(t)$. Where model fitting indicated annual variation in parameter values, we averaged across years to derive an average value for our models. The full structure and mathematical details of the transition matrix are given in the appendix in the online edition of the American Naturalist.

After parameterizing population models to account for habitat-specific differences in aboveground demography, seed dormancy, and density dependence, we used these models to infer how seed predation by mice and seedling herbivory by voles influence lupine population abundance and seed bank abundance in the adjacent dune and grassland habitats. To do this, we first used our best estimates of all parameters and varied seed predation rates and seedling herbivory rates, together and in isolation, to evaluate the influence of these small mammals. We ran four comparisons for each habitat, using (1) control levels of seed predation and seedling survival, (2) seedling survival in the absence of voles (but control levels of seed predation), (3) seed survival in the absence of mice (but control levels of seedling survival), and (4) both seed and seedling survival rates in the absence of mice and voles. As stated previously, although our experiments did not independently manipulate voles and mice, demographic effects could easily be partitioned between these consumers because of the specificity of life stages they attacked. Because our models included density-dependent effects, the asymptotic population growth rate, $\lambda$, and the equilibrium population size are both of interest. Analytical $\lambda$ is informative as a relative measure of population growth when density is low, a situation that occurs periodically in grasslands after populations recover from mass ghost moth dieoffs (Strong et al. 1995), while equilibrium population size provides a longer-term assessment of the population-level effects of consumers. From our model runs, we report the short-term population growth rate (analytical $\lambda$ when holding cover $=0$ ), the number of aboveground plants in the population at equilibrium, and the number of seeds in seed bank at equilibrium. Populations were always started with 100 seeds and 0 adults, and equilibrium conditions were evaluated at $t=300$ years.

To test the robustness of our model results to parameter uncertainty, we ran the same four model comparisons as a bootstrap analysis starting with the original data sets, as suggested by Caswell (2001). For each bootstrap simulation ( $n=1,000)$, we sampled our demographic data with replacement, recalculated all parameters from the bootstrapped data, and reran population models to calculate short-term $\lambda$, aboveground population size, and seed bank size. For each bootstrap estimate of seed germination and predation, we first used the best-fit models to estimate germination from a bootstrap data set of exclusion plots and then fit the best-fit seed predation model to a boot- strap data set of control plots to estimate habitat-specific seed predation rates. We report mean population metrics from the bootstrap analysis along with 95\% confidence intervals (CIs) for each model comparison in each habitat.

To evaluate more generally how seed dormancy and density-dependent seedling survival mediate the effects of seed predation and seedling survival in this system, we ran population projections with and without seed and seedling predators while varying the strength of seed germination (i.e., dormancy) and density dependence. Seed dormancy and density-dependent seedling survival were varied across the range of values that spanned those found in grassland and dune populations. For each level of seed germination, we held a seed's lifetime probability of germinating constant by varying seed survival in the soil. In this way, we did not artificially reduce lupine fecundity in these projections. To alter the strength of density-dependent seedling survival, we varied the value of $\beta_{3}$ in the Ricker equation. For these projections, we report short-term $\lambda$, the equilibrium size of aboveground plants, and the equilibrium size of the seed bank.

\section{Results}

\section{Stage-Specific Survival, Growth, and Reproduction}

Although we assumed an analogous matrix structure in both habitats, substantial differences were found in several demographic rates between habitats. In addition to displaying differences in seed and seedling demography, lupines inhabiting grasslands had higher growth rates and higher rates of stage-specific seed production than did plants growing in dunes (table 1).

\section{Seedling Germination}

Fitted models that linked seed bank size and annual seed production to seedling emergence revealed strong differences in emergence rates between dunes and grasslands. The maximum-likelihood estimate of seedling emergence rate was nearly seven times higher in the dune habitat (mean $=0.014$; range $0.005-0.029$ across years) than in the grassland habitat (mean $=0.0020$; range $0.0006-0.0041$ across years), with strong annual variation (fig. 2). The likelihood profile $95 \%$ confidence limit for the "hab" parameter (table 2) did not contain 0 (maximum-likelihood estimate: 1.96; range 1.65-2.28), and bootstrapped 95\% confidence intervals for annual germination rates between habitats did not overlap, indicating that these mean estimates are robust to parameter uncertainty. Thus, order-of-magnitude differences in seedling emergence exist between habitats, with much higher emergence rates in the dune habitat. These results are consistent with empirical estimates of emergence 
Table 1: Parameterized transition matrices for dune and grassland habitats

\begin{tabular}{|c|c|c|c|c|c|c|c|c|c|}
\hline & Seeds & 1 year & Stage 3 & Stage 4 & Stage 5 & Stage 6 & Stage 7 & Stage 8 & Stage 9 \\
\hline \multicolumn{10}{|c|}{ Dune habitat: } \\
\hline Seeds & .56 & 6.1 & 5.2 & 30.7 & 50.2 & 50.0 & 82.3 & 154.1 & 189.4 \\
\hline 1 year & .003 & 0 & 0 & 0 & 0 & 0 & 0 & 0 & 0 \\
\hline Stage 3 & 0 & .35 & .38 & .10 & .06 & .06 & .05 & .02 & .15 \\
\hline Stage 4 & 0 & .21 & .15 & .15 & .13 & .07 & .03 & 0 & 0 \\
\hline Stage 5 & 0 & .09 & .08 & .26 & .12 & .08 & .07 & .08 & 0 \\
\hline Stage 6 & 0 & .03 & .04 & .14 & .16 & .09 & .09 & .08 & 0 \\
\hline Stage 7 & 0 & .03 & .02 & .17 & .32 & .39 & .41 & .24 & 0 \\
\hline Stage 8 & 0 & 0 & 0 & .02 & .07 & .05 & .18 & .24 & .30 \\
\hline Stage 9 & 0 & 0 & 0 & 0 & 0 & 0 & .01 & .18 & .30 \\
\hline \multicolumn{10}{|c|}{ Grassland habitat: } \\
\hline Seeds & .72 & 237.5 & 423.7 & $1,174.2$ & $1,910.7$ & $2,020.7$ & $1,884.2$ & $2,472.4$ & $2,573.3$ \\
\hline 1 year & .0002 & 0 & 0 & 0 & 0 & 0 & 0 & 0 & 0 \\
\hline Stage 3 & 0 & .04 & .19 & .10 & .10 & .07 & .08 & .05 & .09 \\
\hline Stage 4 & 0 & .05 & .19 & .13 & .06 & .06 & .03 & .07 & .07 \\
\hline Stage 5 & 0 & .07 & .10 & .13 & .06 & .07 & .06 & .02 & 0 \\
\hline Stage 6 & 0 & .04 & .07 & .13 & .08 & .10 & .07 & .03 & .03 \\
\hline Stage 7 & 0 & .04 & .05 & .22 & .39 & .32 & .35 & .22 & .21 \\
\hline Stage 8 & 0 & .00 & .02 & .06 & .12 & .17 & .13 & .24 & .07 \\
\hline Stage 9 & 0 & 0 & 0 & .01 & .04 & .04 & .05 & .12 & .26 \\
\hline
\end{tabular}

Note: Seed production (row 1 ) in the dune matrix is reduced by a seed predation rate of $94 \%$, which was estimated as part of the current study. See appendix for details.

rates that were found to be two to three times higher in dune than grassland habitat (Maron and Simms 1997), and they suggest that emergence rates are likely to be one of the key determinants of differences in seed bank size between habitats. While it is likely that seed survival in the soil is age specific, we believe that our assumption of a constant soil mortality rate is unlikely to change the qualitative results of this study.

\section{Population-Level Rates of Seed Predation}

Of the four alternative seed predation models we tested (comprising the factorial combinations of habitat and year effects), the habitat-only model best fit the data (AIC weight 0.91 ; table 2). The summed AIC weight of the two models with a habitat effect was 0.99 , while the AIC weight of the two models with a year effect was 0.04 . These results indicate substantial differences between dune and grassland habitats in postdispersal seed predation, with little significant annual variation in predation. The maximumlikelihood estimate of the proportion of seeds consumed by mice was 0.94 for the dune habitat and 0 for the grassland habitat. Likelihood profile $95 \%$ confidence intervals on the seed predation rate in the dune $(0.55-1.0)$ and grassland $(0-0.44)$ habitats were nonoverlapping.
Seedling Survival: Effects of Voles and Density Dependence

The Ricker model (eq. [6]) provided a better fit to the plot-level seedling survival data in each habitat than did the Beverton-Holt model (eq. [7]; AIC weights: Ricker $=0.70$, Beverton-Holt $=0.30$ ). Thus, we used the Ricker to assess how vole herbivory and adult plant density jointly influence seedling survival. Likelihood ratio tests on nested models indicated strong effects in both habitats of vole herbivory $\left(\chi^{2}=5.75, P=.0165\right.$; and $\chi^{2}=$

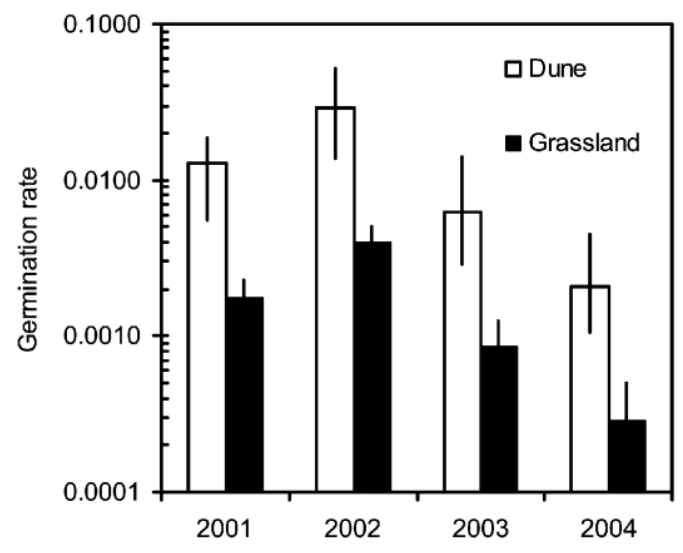

Figure 2: Estimated rates of seedling germination in dune and grassland habitats, spring 2001-2004. Errors bars are 95\% confidence limits from 1,000 bootstrap replicates. 
Table 2: Results of model fitting to estimate habitat-specific rates of seed germination and predation for bush lupine

\begin{tabular}{|c|c|c|c|c|c|}
\hline Model statement & $k$ & $\begin{array}{c}\text { Negative } \\
\text { log likelihood }\end{array}$ & $\mathrm{AIC}_{\mathrm{c}}$ & $\Delta \mathrm{AIC}$ & AIC weight \\
\hline \multicolumn{6}{|l|}{ Germination: } \\
\hline$g_{\text {hab }}=\exp \left[b_{0}+b_{1}(\mathrm{yr} 2)+b_{2}(\mathrm{yr} 3)+b_{3}(\mathrm{yr} 4)+b_{4}(h a b)\right]$ & 5 & 624.3 & $1,258.9$ & .0 & 1.00 \\
\hline$g_{\text {hab }}=\exp \left[b_{0}+b_{1}(\mathrm{yr} 2)+b_{2}(\mathrm{yr} 3)+b_{3}(\mathrm{yr} 4)\right]$ & 4 & 649.4 & $1,307.0$ & 48.1 & .00 \\
\hline \multicolumn{6}{|l|}{ Seed predation: } \\
\hline$p_{\text {new, hab }}=\operatorname{logit}\left[b_{5}+b_{9}(h a b)\right]$ & 2 & 656.1 & $1,316.3$ & .0 & .95 \\
\hline$p_{\text {new, hab }}=\operatorname{logit}\left[b_{5}+b_{6}(\mathrm{yr} 2)+b_{7}(\mathrm{yr} 3)+b_{8}(\mathrm{yr} 4)+b_{9}(\mathrm{hab})\right]$ & 5 & 656.1 & $1,322.4$ & 6.1 & .04 \\
\hline$p_{\text {new, hab }}=\operatorname{logit}\left[b_{5}\right]$ & 1 & 661.9 & $1,325.7$ & 9.4 & .01 \\
\hline$p_{\text {new, hab }}=\operatorname{logit}\left[b_{5}+b_{6}(\mathrm{yr} 2)+b_{7}(\mathrm{yr} 3)+b_{8}(\mathrm{yr} 4)\right]$ & 4 & 661.9 & $1,331.9$ & 15.6 & .00 \\
\hline
\end{tabular}

Note: Germination models were fitted to plots closed to rodents to exclude the influence of seed predators. Seed predation models were fitted to plots open to rodents with fixed annual germination rates specific to each habitat.

16.53, $P<.0001$, for dunes and grasslands, respectively) and total plant cover $\left(\chi^{2}=30.37, P<.0001\right.$; and $\chi^{2}=$ $27.89, P<.0001$, for dunes and grasslands, respectively) on seedling survival. The magnitude of vole herbivory on seedling survival was stronger in the grassland habitat, where the difference in seedling survival (at cover $=0$ ) was 0.35 with voles excluded and 0.13 in control plots, compared to differences of 0.34 and 0.21 for exclusion and control plots, respectively, in the dunes (fig. 3). Densitydependent effects of total plant cover, however, were roughly twice as strong in dune habitat $\left(\beta_{3}=0.17,95 \%\right.$ $\mathrm{CI}=0.09-0.25)$ than in the grassland habitat $\left(\beta_{3}=\right.$ $0.08,95 \% \mathrm{CI}=0.04-0.12$ ).

Although the habitats have similar seedling survival when cover is low, the stronger density dependence in the dune habitat suggests that seedling survival is near 0.01 when lupine canopy cover is approximately $25 \%$, whereas in the grasslands, lupine canopy cover has to be near 50\% to achieve such a reduction in seedling survival (fig. 3). One caveat in our estimation of density-dependent seedling survival from observational data is that the true influence of cover is potentially confounded with temporal (i.e., environmental) variation. Because all of our plots were free of adult lupines at the beginning of the study, cover of adult plants is necessarily correlated with time in both dune $(r=0.62, P<.0001)$ and grassland $(r=$ $0.38, P<.0001)$ habitats. While environmental variability undoubtedly influenced seedling survival during our study, we know of no conditions (e.g., drought) that could explain the extremely low rates of seedling survival observed in the last 3 years of the experiment, when cover was high in most plots.

\section{Population Projections}

Models parameterized with empirical estimates of germination and density dependence in both habitats demonstrate that postdispersal seed predation by mice (in the dunes) and seedling herbivory by voles (in both habitats) have strong but habitat-specific population-level consequences for lupines (fig. 4). Seed predation in the dunes decreased analytical $\lambda$ values (holding cover $=0$ ) by $37 \%$ (bootstrap 95\% CI $=29 \%-49 \%$ ), reduced the equilibrium size of aboveground plants by $89 \% \quad(\mathrm{CI}=$ $58 \%-100 \%)$, and depressed seed bank size by $98 \%$ $(\mathrm{CI}=91 \%-100 \%$; fig. 4). These effects are robust to uncertainty in our parameter estimation; 95\% bootstrap replicates of all three population metrics do not overlap between model projections for control populations and those for populations where seed predators are excluded (fig. 4). In contrast to these forceful population-level effects of granivorous mice on dune populations, vole herbivory on seedlings had rather limited effects.

In the adjacent grassland habitat, population projections indicate that even occasional bouts of intensive seedling herbivory by voles (fig. 1), when averaged across years, can have strong population-level consequences. Voles reduced grassland population growth by $15 \% \quad(\mathrm{CI}=$ 10\%-19\%; fig. 4). Because density dependence was estimated to be weaker in grasslands than in dunes, this modest reduction in $\lambda$ strongly influenced the equilibrium population. Model results indicate that voles decrease the equilibrium size of the aboveground population by $63 \%$ $(\mathrm{CI}=44 \%-89 \%)$ and lower the equilibrium seed bank size by roughly $63 \%(\mathrm{CI}=44 \%-89 \%)$. As was the case for dunes, $95 \%$ bootstrap confidence intervals for $\lambda$ and aboveground population size did not overlap between control and vole exclusion model projections but slightly overlapped with regard to final seed bank size (fig. 4). Population projections always resulted in stable equilibrium numbers by the end of the 300-year time horizon, and stable cycles or chaos were never observed across all plausible formulations of the Ricker equation. When mice were excluded in the dunes, damped oscillations were often generated, but these diminished completely within 30-50 years. For both habitats, equilibrium numbers of adults and seeds were in rough accordance with recorded patterns in the field, where grassland habitats have denser stands 


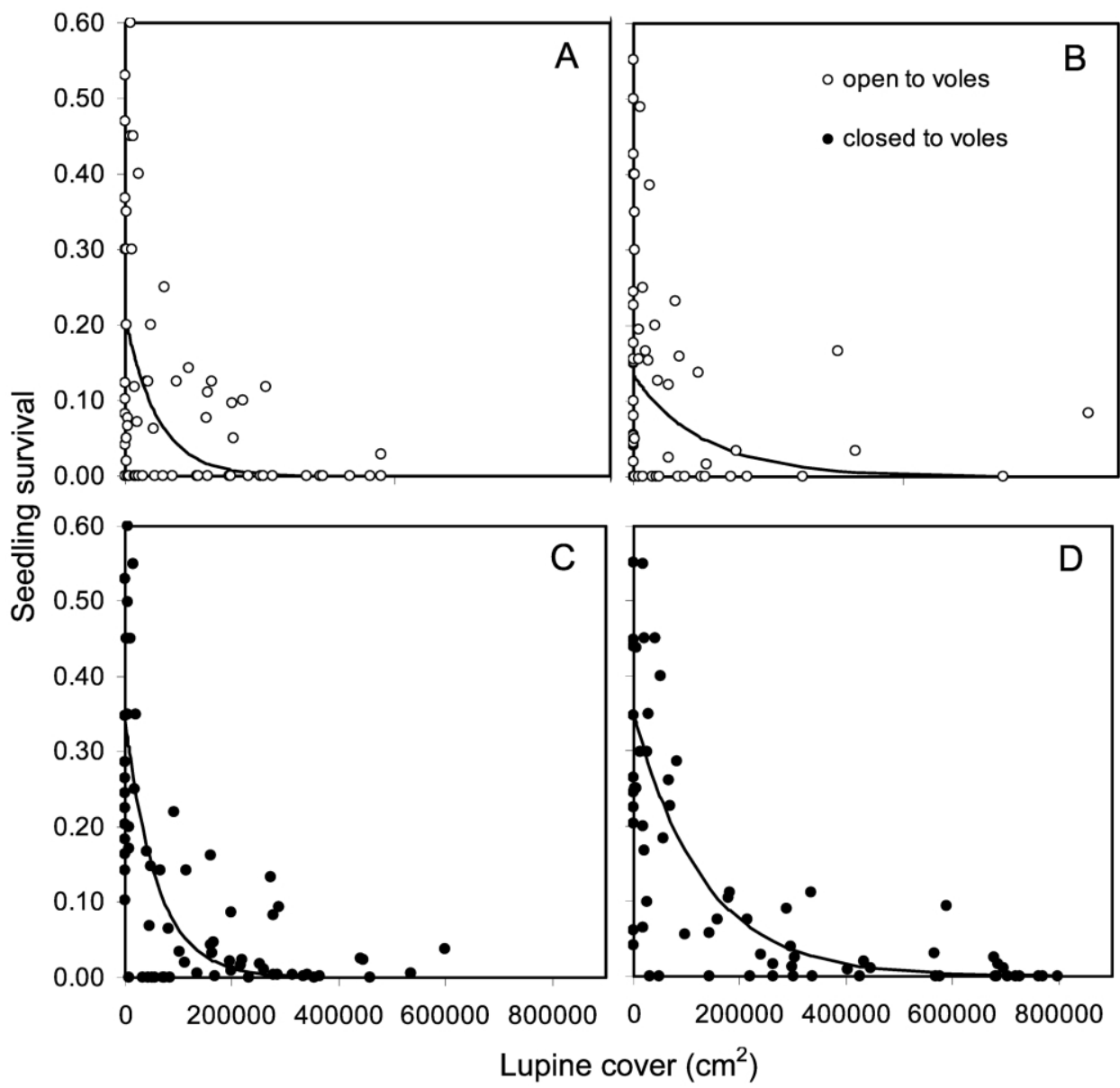

Figure 3: Fitted Ricker functions characterizing the joint influence of vole herbivory and density dependence on lupine seedling survival in dune $(A, C)$ and grassland $(B, D)$ habitats.

of adults and order-of-magnitude-larger seed banks compared to dune habitats (Maron and Simms 1997).

Because we found strong annual variability in germination rates (fig. 2), we ran a separate set of bootstrap population projections with variable germination (choosing each annual germination rate with equal probability) to evaluate the potential influence of this variability on model results. All model results from the population projections with variable germination were qualitatively similar to deterministic projections. Most importantly, the differences in equilibrium population size and seed bank size between treatments were maintained, with nonoverlapping $95 \%$ confidence intervals as in the deterministic projections.

We found that consumers exerted strong control over lupine population performance even when we varied the strength of dormancy and density dependence across a range of values experienced by the dune and grassland life histories. Short-term $\lambda$ increased as dormancy decreased, allowing consumers to have a stronger effect on $\lambda$ when dormancy was low (fig. 5). Increasing dormancy in the dunes reduced the effect of mice from a 39\% decrease in $\lambda$ to a $29 \%$ decrease in $\lambda$. Decreasing dormancy in the grassland increased the negative effect of voles on lupine population growth from a $15 \%$ decrease in $\lambda$ to a $25 \%$ decrease in $\lambda$. However, the effects of dormancy on shortterm $\lambda$ did not translate to differences in the equilibrium population size of adults. Instead, the size of the aboveground population was influenced by the strength of density dependence, allowing consumers (mice in the dunes, voles in the grasslands) to have stronger effects when density dependence was weak (fig. 6). The size of the seed bank at equilibrium was jointly influenced by dormancy and density dependence. This mediated the effect of consumers, allowing them to have their largest impacts on 

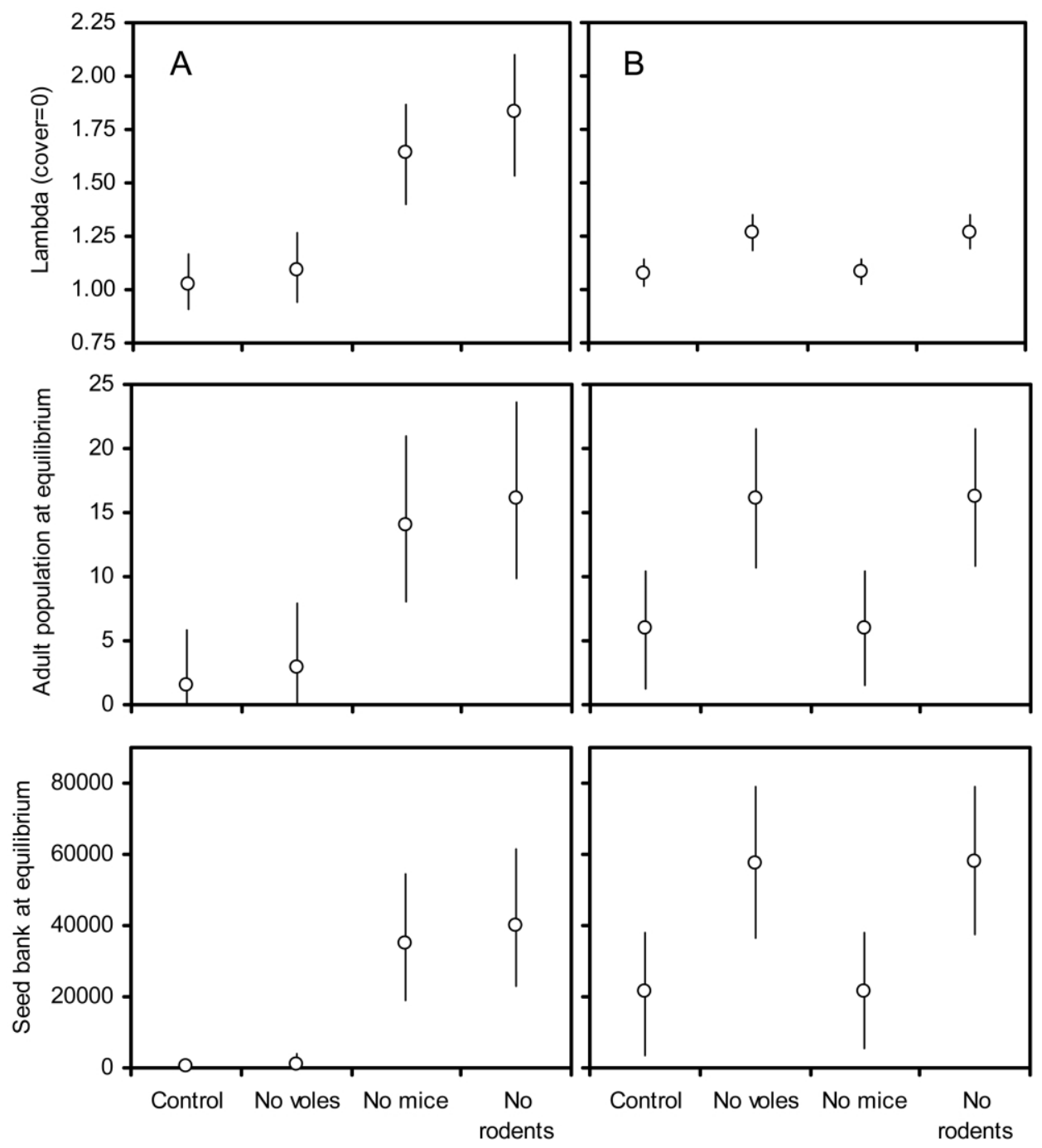

Figure 4: Effects of consumers on lupine population metrics in dune $(A)$ and grassland $(B)$ habitats. Means and $95 \%$ confidence limits are presented from 1,000 bootstrap replicates.

seed banks when dormancy was high and density dependence was weak (fig. 6).

\section{Discussion}

Population models parameterized with experimental demographic data clearly indicate that different small mammal consumers can have substantial, lasting impacts on the population growth and dynamics of a perennial plant with a seed bank. The strength of these effects-in the face of density-dependent seedling survival and a persistent seed bank-suggests that the conditions under which consumers such as these exert effects on plant population abundance may be more common than previously thought. Louda and Potvin (1995) predicted that shortlived perennials or fugitive plants with a heavy reliance on current seed production should be most sensitive to the negative population-level effects of seed consumers. What is less clear, however, is how seed or seedling consumption influences the dynamics of woody plants, particularly those with seed banks. Our results highlight the fact that the mere presence of seed dormancy and density dependence does not eliminate consumer impacts on plant abundance. Rather, it is the strength of these processes that shapes consumer influences (Maron and Gardner 2000). This argues for quantitative, rather than qualitative, assessments of how population processes mediate plant-consumer impacts (Ehrlén 2002). 

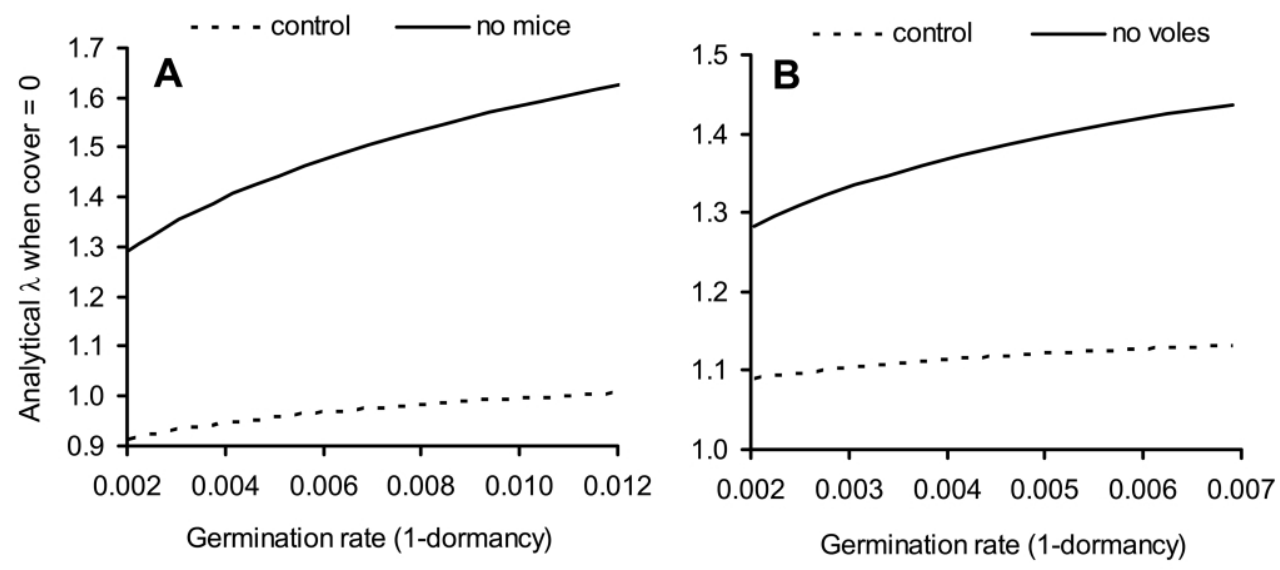

Figure 5: Influence of dormancy on the density-independent analytical $\lambda$ in the dune $(A)$ and grassland $(B)$ habitats. For each habitat, $\lambda$ under control conditions is charted along with $\lambda$ when mice (in the dunes) or voles (in the grasslands) are excluded.

It has long been known that both voles and granivorous mice can have substantial impacts on seed and seedling survival. Voles, particularly at population highs, can have devastating effects on vegetation (Batzli and Pitelka 1970; Ostfeld and Canham 1993; Ostfeld et al. 1997; Sirotnak and Huntly 2000; Manson et al. 2001; Howe et al. 2002), particularly in old fields, where they strongly reduce tree seedling recruitment (De Steven 1991; Gill and Marks 1991; Ostfeld and Canham 1993; Ostfeld et al. 1997; Manson et al. 2001). Granivorous mice have similarly strong effects on seedling recruitment (Edwards and Crawley 1999; Cummings and Alexander 2002). These varied impacts, however, have seldom been examined from a population perspective. Furthermore, plant ecologists seldom directly connect commonly observed variation in consumer pressure across environments (Holloway 1957; Louda 1982; Lincoln and Mooney 1984; Galen 1990; Louda and Rodman 1996; DeWalt et al. 2004) with habitatspecific patterns in plant abundance or dynamics (but see Louda and Rodman 1996). In most cases, differences in plant abundance across habitats or environmental gradients are usually ascribed to abiotic factors that vary between habitats rather than to differences in consumer pressure. Results from this study show that different consumers can determine patterns of plant abundance in adjacent habitats and that habitat-specific demography interacts with habitat-specific impacts of consumers to shape adult plant and seed bank abundance in each habitat.

The strong habitat-dependent effects of voles on bush lupine may result from differences between habitats in vole abundance. While we do not have direct estimates of this, grassland habitat at our study site has greater cover and is probably a more suitable habitat for voles than is dune habitat. In contrast, the difference between habitats in seed predation is probably not a result of differences in mouse abundance (Maron and Simms 2001) but rather a result of the greater vulnerability of lupine seeds in open dune habitat than in grasslands.

Our results provide new insights into the role that seed dormancy, alone and in concert with density-dependent seedling survival, plays in mediating consumer effects. In our population models, increasing seed dormancy lowered deterministic $\lambda$ (fig. 5). Because we held the probability of germination over a seed's lifetime constant (by adjusting rates of survival in the soil), the reduction in $\lambda$ with increased seed dormancy results from the effect of delayed reproduction on the multiplicative rate of population growth. However, in addition to reducing $\lambda$ in control populations, increasing dormancy also slightly reduced the influence of consumers on short-term population growth rate $(\lambda$ when cover $=0$; fig. 5$)$. Seed dormancy mediates the effects of consumers on density-independent population growth by changing the influence of seeds on $\lambda$; with less dormancy, seeds have greater direct effects on $\lambda$, allowing consumers of seeds (and seedlings) to have greater impacts on $\lambda$. This result holds for both seed predation by mice in dunes and seedling herbivory by voles in grasslands. However, dormancy has a stronger buffering influence on the population-level effect of seed predation than it does on seedling herbivory (fig. 5). Our results point to a general gap in our understanding of how seed banks influence aboveground dynamics of plants (Kalisz and McPeek 1992; Cabin et al. 2000; Doak et al. 2002) and suggest that additional studies that focus on uniting seed bank and aboveground dynamics are needed.

Interestingly, the increase in $\lambda$ with decreasing dormancy does not translate to increases in the equilibrium population of aboveground plants over the range of rates 

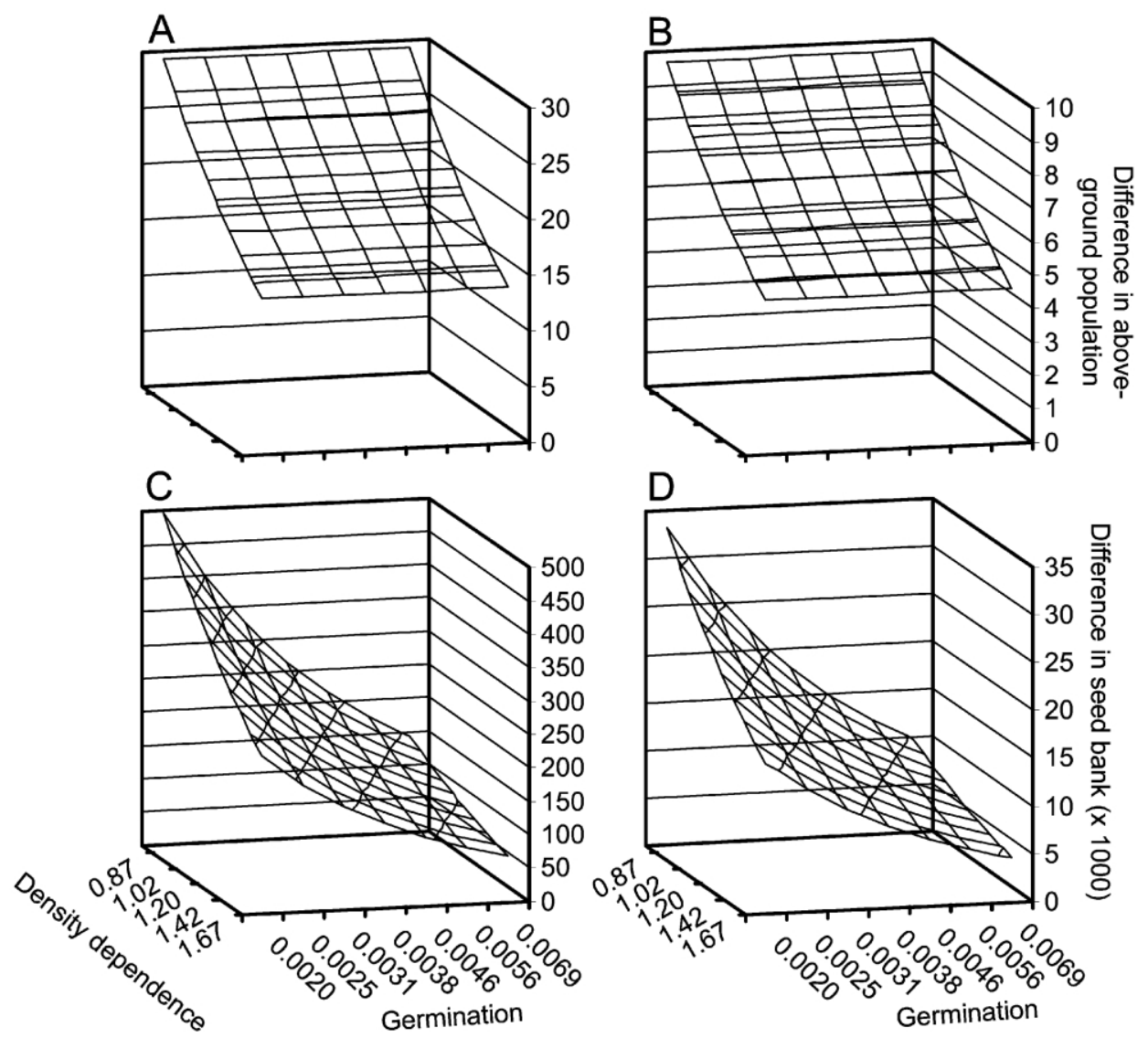

Figure 6: Combined influence of seed dormancy and density-dependent seedling survival on the effect of mice on the equilibrium size of aboveground plants $(A)$ and seeds $(C)$ in the dunes and on the effect of voles on the equilibrium size of aboveground plants $(B)$ and seeds $(D)$ in the grassland habitat. The strengths of dormancy and density dependence were varied over their ranges in dune and grassland habitats. The rate of seed survival in the seed bank was varied with the emergence rate such that the probability of a seed emerging over its lifetime was held constant. The densitydependence axis charts the value of $\beta_{3}(\times 10,000)$ in equation (6).

of germination and density dependence estimated for the dune and grassland life histories (fig. 6). Instead, the change in the aboveground population in these projections is determined solely by the strength of density dependence. Thus, density dependence in our models appears to eliminate the cost of seed dormancy for the aboveground population. This happens because at the equilibrium, the same number of seeds germinate each year, regardless of whether they originate as a large germinating fraction of young seeds (when dormancy is low) or a tiny germinating fraction of a vast seed bank (when dormancy is high). Thus, at equilibrium, the delayed reproduction of the highdormancy life history (which causes the decrease in shortterm $\lambda$; fig. 5) "catches up" to that of the less dormant life history to produce an equivalent number of seedlings in the next generation.

While compensatory density-dependent seedling mortality is commonly given as a major reason why consumers may seldom limit plant populations (Crawley 1989, 1992), few studies have quantified the strength of such density dependence, let alone incorporated it into population models used to infer consumer impacts on plants. Harper's (1977) early contention that there is a "tolerable" amount of seed predation that, because of density-dependent seedling survival, will not affect the plant population has dominated ecologists' thinking for some time. This reasoning requires that the form of density dependence be fully compensating, whereby there is a set maximum number of seedlings that can survive. All excess seeds (and the seedlings that recruit from them) are simply eliminated by density-dependent processes. In our model, we used empirical estimates of seedling survival, which monotonically decrease as a function of total lupine cover. Thus, voles reduce the baseline seedling survival rates, and their effect on equilibrium population size is mediated by the equilibrium amount of adult lupine cover (fig. 3). One caveat 
to our conclusions is that we did not assess density effects on demographic rates other than seedling survival. To the extent that strong density dependence operates on other life stages, this could compensate for consumer effects to a larger extent than we have estimated in our population models.

To explore in more detail how the strengths of density dependence and seed dormancy mediate consumer effects on lupine populations, we varied these rates and examined how the magnitude of consumer effect changed in parameter space. Density dependence had a simple nonlinear influence on the magnitude of the consumer effect on equilibrium population size of aboveground plants (fig. 6). Not surprisingly, the population effects of both seedling herbivory and seed predation decreased as the strength of density-dependent seedling survival increased. Densitydependent seedling survival mediates consumer effects on seeds and seedlings by lowering the reproductive value of these life stages and reducing the population-level importance of animals that consume them. In our system, however, density-dependent seedling survival is not strong enough to eliminate specific consumer effects, and lupine populations are ultimately limited by high seed and seedling death due to consumers (fig. 6).

Our model revealed that in addition to affecting aboveground population size, consumers can have dramatic and lasting effects on the size of the lupine seed bank. Model projections of dune populations where seed predators are excluded yield a mean seed bank size of approximately 35,742 seeds, which is more than an order of magnitude higher than the 662 seeds persisting in the control projections (fig. 4). In the grasslands, protecting seedlings from occasional high bouts of vole herbivory can more than double the long-term size of the seed bank. This study suggests that the more abundant seed bank that we typically find in grassland versus dune habitat (roughly four times greater in grasslands than dunes) is due not only to higher seed dormancy but also to reduced seed predation by mice in that habitat. Spatial variation in seed bank density is often ascribed to variation in the cues that trigger germination, in addition to physical (i.e., genetic) determinants of seed dormancy (Baskin and Baskin 1998). However, for a given rate of germination and dormancy, seed bank size can be critically affected by consumers that reduce the number of seeds entering the belowground seed pool.

Previous studies have shown that ghost moth (Hepialus californicus) herbivory kills adult lupines, driving boombust dynamics in grasslands (Strong et al. 1995; Maron 1998, 2001). However, during our 5.5-year demographic study, in which we experimentally kept lupines free of these root-boring insects, we found no effects of these herbivores on adult plant survival or fecundity (Maron and Kauffman
2006). Thus, our population model does not depict the kind of dynamics for lupines in grasslands that are sometimes seen empirically. However, our goal in modeling consumer effects was not to fully mimic the rich range of population dynamics that lupines exhibit in grasslands. Instead, we have explored how variation in plant life history (i.e., differences between grassland and dune populations in adult growth rates and seed dormancy) interacts with density dependence to mediate how consumers influence plant populations. Our results suggest that even in the absence of strong effects by one consumer, other consumers may exert lasting effects.

It is logical to assume that herbivory and granivory on early life stages (i.e., seeds and seedlings) of perennial plants are unlikely to produce population-level impacts because the sensitivity of $\lambda$ to these vital rates is typically quite low (Silvertown et al. 1993; Franco and Silvertown 2004). In contrast, adult survival often has a much larger influence on $\lambda$ than the same proportional change in seed survival or germination. However, lost in this line of reasoning is the fact that the demographic rates of seeds and seedlings are typically much more variable than those of adult plants (Howe and Miriti 2004). Damage or outright loss of these life stages due to consumers can bring about much larger demographic changes still. Our results illustrate this point. In both grasslands and dunes, different consumers had strong effects on the vital rates of seeds and seedlings. However, growth and survival of large size classes were fairly similar between grassland and dune populations (table 1), and consumers have little impact on these transitions (Maron and Kauffman 2006). Yet, in both habitats, effects of consumers on early life stages had meaningful effects on projected population sizes of plants by bringing about large changes in these vital rates. Thus, current thinking regarding the unimportance of consumer-driven changes to seed and seedling demography for overall population growth may often be incorrect when it is not tempered by knowledge of the magnitude of demographic change imposed by consumers. If large enough, changes to vital rates of low elasticity can bring about meaningful population-level effects (Gaillard et al. 2000).

The broad message from this work is that understanding the degree to which herbivores influence plant population dynamics requires estimating their effects on particular vital rates and then incorporating them into a quantitative population framework. This approach is rare, not only for native plant-native consumer studies but also for those that examine the effects of biocontrol agents on plants (McEvoy and Coombs 1999), plant-pollinator dynamics and pollen limitation (Ashman et al. 2004), and plantseed dispersal interactions (Godínez-Alvarez et al. 2002; Howe and Miriti 2004). Understanding how plant distri- 
bution and abundance are influenced by biotic interactions requires understanding how sensitive population growth is to particular demographic rates, in addition to quantifying the magnitude of consumer effects on these rates.

\section{Acknowledgments}

This work benefited greatly from early input and field help from E. Simms. We greatly thank the many field assistants who helped over the years with the collection of demographic data on bush lupine. P. Connors and R. Tinsman greatly facilitated our work on the Bodega Marine Reserve and the University of California Bodega Marine Laboratory. M. Bricker, E. Crone, and D. Doak read earlier versions of the manuscript and provided valuable comments. This work was supported by National Science Foundation grant DEB-9726551 to J.L.M.

\section{Literature Cited}

Andersen, A. N. 1988. Insect seed predators may cause far greater losses than they appear to. Oikos 52:337-340.

- 1989. Pre-dispersal seed losses to insects in species of Leptospermum (Myrtaceae). Australian Journal of Ecology 14:13-18.

Ashman, T.-L., T. M. Knight, J. A. Steets, P. Amarasekare, M. Burd, D. Campbell, M. Dudash, et al. 2004. Pollen limitation of plant reproduction: ecological and evolutionary causes and consequences. Ecology 85:2408-2421.

Auld, T. D., and P. J. Myerscough. 1986. Population dynamics of the shrub Acacia suaveolens (Sm.) Willd.: seed production and predispersal seed predation. Australian Journal of Ecology 11:219234.

Baskin, C. C., and J. M. Baskin. 1998. Seeds: ecology, biogeography, and evolution of dormancy and germination. Academic Press, San Diego, CA.

Batzli, G. O., and F. A. Pitelka. 1970. Influence of meadow mouse populations in California grassland. Ecology 51:1027-1039.

Burnham, K. P., and D. R. Anderson. 2002. Model selection and multimodel inference: a practical information-theoretic approach. 2nd ed. Springer, New York.

Cabin, R. J., D. L. Marshall, and R. J. Mitchell. 2000. The demographic role of soil seed banks. II. Investigations of the fate of experimental seeds of the desert mustard Lesquerella fendleri. Journal of Ecology 88:293-302.

Caswell, H. 2001. Matrix population models. 2nd ed. Sinauer, Sunderland, MA.

Cates, R. G. 1975. The interface between slugs and wild ginger: some evolutionary aspects. Ecology 56:391-400.

Crawley, M. J. 1989. Insect herbivores and plant population dynamics. Annual Review of Entomology 34:531-564.

-1992. Seed predators and plant population dynamics. Pages 157-192 in M. Fenner, ed. Seeds, the ecology of regeneration in plant communities. CAB International, Wallingford.

- 1997. Plant-herbivore dynamics. Pages 401-474 in M. J. Crawley, ed. Plant ecology. Blackwell Scientific, Oxford.

Cummings, C. L., and H. M. Alexander. 2002. Population ecology of wild sunflower: effects of seed density and post-dispersal vertebrate seed predators. Oecologia (Berlin) 130:274-280.
DeSteven, D. 1991. Experiments on mechanisms of tree establishment in old-field succession: seedling emergence. Ecology 73:1066-1075.

DeWalt, S. J., J. S. Denslow, and K. Ickes. 2004. Natural-enemy release facilitates habitat expansion of the invasive tropical shrub Clidemia hirta. Ecology 85:471-483.

Dirzo, R., and J. L. Harper. 1982. Experimental studies on slug-plant interactions. II. The effect of grazing by slugs on high density monocultures of Capsella bursa-pastoris and Poa annua. Journal of Ecology 68:999-1011.

Doak, D. F., D. Thomson, and E. S. Jules. 2002. Population viability analysis for plants: understanding the demographic consequences of seed banks for population health. Pages 312-337 in S. R. Beissinger and D. R. McCullough, eds. Population viability analysis. University of Chicago Press, Chicago.

Edwards, G. R., and M. J. Crawley. 1999. Rodent seed predation and seedling recruitment in mesic grassland. Oecologia (Berlin) 118: 288-296.

Ehrlén, J. 1995. Demography of the perennial herb Lathyrus vernus. II. Herbivory and population dynamics. Journal of Ecology 83: 297-308.

- 1997. Spatiotemporal variation in predispersal seed predation intensity. Oecologia (Berlin) 108:708-713.

- 2002. Assessing the lifetime consequences of plant-animal interactions for the perennial herb Lathyrus vernus (Fabaceae). Perspectives in Plant Ecology Evolution and Systematics 53:145163.

-2003. Fitness components versus total demographic effects: evaluating herbivore impacts on a perennial herb. American Naturalist 162:796-810.

Franco, M., and J. Silvertown. 2004. Comparative demography of plants based upon elasticities of vital rates. Ecology 85:531-538.

Fröborg, H., and O. Eriksson. 2003. Predispersal seed predation and population dynamics in the perennial understory herb Actea spicata. Canadian Journal of Botany 81:1058-1069.

Gaillard, J.-M., M. Festa-Bianchet, N. G. Yoccoz, A. Loison, and C. Toïgo. 2000. Temporal variation in fitness components and population dynamics of large herbivores. Annual Review of Ecology and Systematics 31:367-393.

Galen, C. 1990. Limits to the distributions of alpine tundra plants: herbivores and the alpine skypilot, Polemonium viscosum. Oikos 59:355-358.

Gange, A. C. 1990. Effects of insect herbivory on herbaceous plants. Pages 157-173 in J. J. Burdon and S. R. Leather, eds. Pests, pathogens and plant communities. Blackwell Scientific, Oxford.

Gill, D. S., and P. L. Marks. 1991. Tree and shrub colonization of old fields in central New York. Ecological Monographs 61:183205.

Godínez-Alvarez, H., A. Valiente-Banuet, and A. Rojas-Martinez. 2002. The role of seed dispersers in the population dynamics of the columnar cactus Neobuxbaumia tetetzo. Ecology 83:2617-2629.

Goheen, J. R., F. Keesing, B. F. Allan, D. Ogada, and R. S. Ostfeld. 2004. Net effects of large mammals on Acacia seedling survival in an African savanna. Ecology 85:1555-1561.

Hanley, M. E., M. Fenner, and P. J. Edwards. 1995. An experimental field study of the effects of mollusc grazing on seedling recruitment and survival in grassland. Journal of Ecology 83:621-627.

Harper, J. L. 1977. Population biology of plants. Academic Press, New York.

Hendrix, S. D. 1984. Reactions of Heracleum lanatum to floral herbivory by Depressaria pastinacella. Ecology 65:191-197. 
Herrera, C. M., M. Medrano, P. J. Rey, M. Sanchez-Lafuente, M. B. Garcia, J. Guitian, and A. J. Manzaneda. 2002. Interaction of pollinators and herbivores on plant fitness suggests a pathway for correlated evolution of mutualism- and antagonism-related traits. Proceedings of the National Academy of Sciences of the USA 99: 16823-16828.

Hilborn, R., and M. Mangel. 1997. The ecological detective: confronting models with data. Monographs in population biology 28 . Princeton University Press, Princeton, NJ.

Holloway, J. K. 1957. Weed control by insects. Scientific American 197:56-62.

Holmstrom, H. K. 1999. The TOMLAB optimization environment in Matlab. Advanced Modeling and Optimization 1:47-69.

Howe, H. F., and M. N. Miriti. 2004. When seed dispersal matters. BioScience 54:651-660.

Howe, H. F., J. S. Brown, and B. Zorn-Arnold. 2002. A rodent plague on prairie diversity. Ecology Letters 5:30-36.

Hulme, P. E. 1994. Rodent post-dispersal seed predation in grassland: magnitude and sources of variation. Journal of Ecology 82:645652 .

. 1998. Post-dispersal seed predation: consequences for plant demography and evolution. Perspectives in Plant Ecology Evolution and Systematics 1:32-46.

Hunter, M. D. 1992. Interactions within herbivore communities mediated by the host plant: the keystone herbivore concept. Pages 288-325 in M. D. Hunter, T. Ohgushi, and P. W. Price, eds. Effects of resource distribution on animal-plant interactions. Academic Press, New York.

Huntly, N. 1991. Herbivores and the dynamics of communities and ecosystems. Annual Review of Ecology and Systematics 22:477503.

Hyde, E. O. C. 1954. The function of the hilum in some Papilionaceae in relation to the ripening of the seed and the permeability of the testa. Annals of Botany 18:241-256.

Kalisz, S., and M. A. McPeek. 1992. Demography of an age-structured annual: resampled projection matrices, elasticity analyses, and seed bank effects. Ecology 73:1082-1093.

Lefkovitch, L. P. 1965. The study of population growth in organisms grouped by stages. Biometrics 21:1-18.

Lincoln, D. E., and H. A. Mooney. 1984. Herbivory on Diplacus aurantiacus shrubs in sun and shade. Oecologia (Berlin) 64:173176.

Louda, S. M. 1982. Distribution ecology: variation in plant recruitment over a gradient in relation to insect seed predation. Ecological Monographs 52:25-41.

- 1989. Predation in the dynamics of seed regeneration. Pages 25-51 in M. A. Leck, V. T. Parker, and R. L. Simpson, eds. Ecology of soil seed banks. Academic Press, New York.

Louda, S. M., and M. A. Potvin. 1995. Effect of inflorescence-feeding insects on the demography and lifetime fitness of a native plant. Ecology 76:229-245.

Louda, S. M., and J. E. Rodman. 1996. Insect herbivory as a major factor in the shade distribution of a native crucifer (Cardamine cordifolia A. Gray, bittercress). Journal of Ecology 84:229-237.

Manson, R. H., R. S. Ostfeld, and C. D. Canham. 2001. Long-term effects of rodent herbivores on tree invasion dynamics along forestfield edges. Ecology 82:3320-3329.

Maron, J. L. 1998. Individual and joint effects of below- and aboveground insect herbivory on perennial plant fitness. Ecology 79: 1281-1293.
2001. Intraspecific competition and subterranean insect herbivory: individual and interactive effects on bush lupine. Oikos 92:178-186.

Maron, J. L., and S. N. Gardner. 2000. Consumer pressure, seed versus safe-site limitation, and plant population dynamics. Oecologia (Berlin) 124:260-269.

Maron, J. L., and M. J. Kauffman. 2006. Habitat-specific impacts of multiple consumers on plant population dynamics. Ecology 87: 113-124.

Maron, J. L., and E. L. Simms. 1997. Effects of seed predation on seed bank size and seedling recruitment of bush lupine (Lupinus arboreus). Oecologia (Berlin) 111:76-83.

- 2001. Rodent limited establishment of bush lupine: field experiments on the cumulative effect of granivory. Journal of Ecology 89:578-588.

Maron, J. L., S. Harrison, and M. E. Greaves. 2001. Origin of an insect outbreak: escape in space or time from natural enemies? Oecologia (Berlin) 126:595-602.

Marquis, R. J. 1992. The selective impact of herbivores. Pages 301325 in R. S. Fritz and E. L. Simms, eds. Plant resistance to herbivores and pathogens. University of Chicago Press, Chicago.

McEvoy, P. B., and E. M. Coombs. 1999. Biological control of plant invaders: regional patterns, field experiments, and structured population models. Ecological Applications 9:387-401.

Mittelbach, G. G., and K. L. Gross. 1984. Experimental studies of seed predation in old-fields. Oecologia (Berlin) 65:7-13.

Morris, W. F., and D. F. Doak. 2002. Quantitative conservation biology: theory and practice of population viability analysis. Sinauer, Sunderland, MA.

Ostfeld, R. S., and C. D. Canham. 1993. Effects of meadow vole population density on tree seedling survival in oldfields. Ecology 74:1792-1801.

Ostfeld, R. S., R. H. Manson, and C. D. Canham. 1997. Effects of rodents on survival of tree seeds and seedlings invading old fields. Ecology 78:1531-1542.

Parker, M. A., and A. G. Salzman. 1985. Herbivore exclosure and competitor removal: effects on juvenile survivorship and growth in the shrub Gutierrezia microcephala. Journal of Ecology 73:903919.

Rolston, M. P. 1978. Water impermeable seed dormancy. Botanical Review 44:365-396.

Rose, K. E., S. M. Louda, and M. Rees. 2005. Demographic and evolutionary impacts of native and invasive insect herbivores on Cirsium canescens. Ecology 86:453-465.

Seber, G. A. F., and C. J. Wild. 1989. Nonlinear regression. Wiley, New York.

Silvertown, J., M. Franco, I. Pisanty, and A. Mendoza. 1993. Comparative plant demography: relative importance of life-cycle components to the finite rate of increase in woody and herbaceous perennials. Journal of Ecology 81:465-476.

Sirotnak, J. M., and N. J. Huntly. 2000. Direct and indirect effects of herbivores on nitrogen dynamics: voles in riparian areas. Ecology 81:78-87.

Stowe, K. A., R. J. Marquis, C. J. Hochwender, and E. L. Simms. 2000. The evolutionary ecology of tolerance to consumer damage. Annual Review of Ecology and Systematics 31:565-595.

Strauss, S. Y., and A. R. Zangerl. 2002. Plant-insect interactions in terrestrial ecosystems. Pages 77-106 in C. M. Herrera and O. Pellmyr, eds. Plant-animal interactions. Blackwell Science, Oxford.

Strong, D. R., J. L. Maron, P. G. Connors, A. Whipple, S. Harrison, 
and R. L. Jefferies. 1995. High mortality, fluctuation in numbers, and heavy subterranean insect herbivory in bush lupine, Lupinus arboreus. Oecologia (Berlin) 104:85-92.

Van Mourik, T. A., T. J. Stomph, and A. J. Murdoch. 2005. Why high seed densities within buried mesh bags may overestimate depletion rates in soil seed banks. Journal of Ecology 42:299-305.
Zammit, C., and C. W. Hood. 1986. Impact of flower and seed predators on seed-set in two Banksia shrubs. Australian Journal of Ecology 11:187-193.
Associate Editor: Tia-Lynn Ashman Editor: Jonathan B. Losos 